\title{
Sustainability from Household and Infrastructure Innovations
}

By

Peter ALLEN ${ }^{1}$, Eugene BUTANS ${ }^{1}$, Marguerite ROBINSON ${ }^{1}$, Liz VARGA ${ }^{2}$

\begin{abstract}
In this paper, we look at the impact of different possible changes and innovations in the national/regional infrastructure and of individual households on the reduction of their material 'footprint' and carbon emissions. We have developed an 'agent-based model' (ABM) that explores the impact of possible changes in regional infrastructure and in 'household agent' behaviour and lifestyles. We study households of the UK, Germany, Spain and Finland, and calculate the overall effects of the diffusion of such changes and innovations. The 'lifestyle' of households is divided into four different 'domains' - Living, Food, Mobility and Energy. For each change, the model shows the linked effects of adoption, and total household input requirements (materials, energy etc.), household and food wastes and $\mathrm{Co} 2$ emissions. This informs policy concerning which modifications will be most effective. We can also estimate approximately how much 'clean' electricity will be needed in each country for households needs and their electric vehicles.
\end{abstract}

KEYWORDS: Sustainability, Household Changes and Innovations, ABM model, Household System, Material Footprints, Clean Electricity

1. School of Management, Cranfield University, Bedford, MK43 OAL, UK

2. Department of Civil, Environmental \& Geomatic Engineering, Chadwick Building, Gower Street, London WC1E 6BT 


\section{Introduction}

Following the recent IPCC Report on climate change [1] it is clear, if it wasn't before, that there is an urgent need for action on carbon emissions and waste production. In order to help decide which actions should be taken and the policies that need to be adopted in different countries, we have developed the model that is described here. We have designed the model to look at how the diffusion of specific changes and innovations could affect current environmental impacts of a particular region. This is really a model of the diffusion of 'climate emergency' changes and innovations aimed at households and urban, regional and national authorities. Our model provides support for prioritizing decisions and policies that can have the most positive effect on the impending disaster.

In a recent paper, an Agent Based Model (ABM) model was developed that examined the impact of possible household changes and innovations [2] and here we consider the importance of additional infrastructure reforms that can reduce the material footprint and $\mathrm{CO} 2$ emissions and get closer to sustainability. The model aims to provide a way of estimating the reduced impacts of households, and the production systems that serve them, on the environment. Indeed, the whole question of our long term survival is largely about finding how the needs of a population can be met by sustainable systems of production - that is from renewables. We need to move our annual production and consumption patterns to ones that fit what the earth can provide - in other words, greatly reduce them.

In our previous papers and publications over many years, we have stressed the idea that human systems, with social, economic, historical and cultural elements are complex. And in our earlier works we have stressed that these are not mechanical systems with fixed equations and processes. Complexity leads to symmetry breaking events and creative evolutionary behaviours which, over time, make pre-existing models qualitatively wrong $[3,4,5,6]$. This demonstrates the limits to knowledge and prediction. New processes, relationships, structures and problems 
will arise in a real complex system such as an ecosystem. Clearly, until now, societies have predominantly adopted a simple exploitative paradigm in economic development, and now finally we are facing the possibility of massive collapse and failure if we continue in this old way. Here, however, in this paper we want to simply make some fairly straightforward calculations about reductions that could be made to the material footprint and emissions of our current societies. We need to change what we have been doing. In order to help make this change we therefore do some calculations about how, practically, we could reduce our material footprint and our emissions, as a first step towards a new way forward. We have always stressed the creativity of complex systems and of coevolution, and encouraged a move away from a simple slash and burn exploitation of the natural world. We thoroughly support a move towards a 'regenerative approach' that considered the self-organizing properties of ecosystems and took us to a new, more satisfactory and sustainable way of life $[7,8,9,10]$. Here, however, we are limiting ourselves to the first steps of this change, and we try simply to show what needs to be done now, if we are to avoid a major disaster. If we can avoid disaster, then we must move to more complex and regenerative ideas and actions.

Households are one of the largest contributors globally to carbon emissions. But the 2008 Climate Change Act requires: a) 34\% cut in 1990 greenhouse gas emissions by 2020, and b) at least an $80 \%$ cut in 1990 emissions by 2050 . Meeting these targets will require many changes [11]. Urban areas are responsible for in excess of $70 \%$ of these [12]. In Ivanova et al. 2015 [13], the environmental impact of household consumption is studied using a multiregional inputoutput database. They look at the Carbon, Land, Materials and Water Footprints per individual for different countries. This shows the collective impact of Households on the environment, revealing the overall effects of different situations and lifestyles. A recent review [14] has looked at the literature on innovations in organizations, supply chains, and communities that can help us towards a sustainable future. Many of the articles are encouraging as we make progress toward a sustainable society through innovation and change.

In our study here, however, we are concerned with how far potential changes and innovations made by households might reduce household demands on the environment, whilst retaining the natural diversity of household behaviours within each study. Reducing the emissions 
caused both directly and indirectly by households in our towns and cities is a significant international challenge. Reductions of $80 \%$ on 1990 levels by 2050 have been promised by the signatories of the Paris Agreement on Climate Change [15]. Clearly changes and innovations for households and the production systems that sustain them, will be key in achieving these changes.

Within households the different human needs that require answering have been divided into different Domains - namely: Living, Food, Mobility and Energy. Clearly, these domains interact as we try to keep warm, to cook our food, dispose of our household and food waste, travel to and from work and to the shops. But our current lifestyles are completely unsustainable over coming decades as we use far too much energy and materials and emit far too much $\mathrm{CO} 2$ (and other Greenhouse gases). For example, on average in the UK the material footprint is around $31,000 \mathrm{kgs}$ of 'inputs' per person per year - where a suggested sustainable level might be around $8,000 \mathrm{kgs}[16,17]$.

In our study here we are concerned with what changes could significantly reduce household demands on the environment, whilst retaining the natural diversity of household behaviours within each study.

In other work [18], the sustainable energy development for the UK was modelled and in addition, an agent-based model for energy service companies [19] was described. More recently, an Agent Based Model was developed that can be used to understand which household innovations can best increase the 'sustainability' of a region or country [2]. The model allowed exploratory simulations of how national infrastructure and households might innovate and change in such a way as to make them more sustainable. Each innovation is tested separately, and this allows comparisons of their effectiveness in different cases to be made and allows an estimation of their combined effects. This can then be compared with what is considered to be a 'sustainable' level.

This research was part of the EU-innovate Research programme (see acknowledgements) coordinated by the Technical University of Munich. This was linked to the papers and reports from the Wuppertal Institute and from researchers in Finland, [20], a possible sustainable 
material footprint per individual per year has been calculated at around $8000 \mathrm{kgs}$. This has influenced our work here. However, we do not consider this as a 'fixed' target, as the circumstances and issues may well change as climatic and ecological factors evolve. So here we examine the practical issues involved in reducing the material footprint per person to a much lower level than at present. [21]. (MIPS - the Material Input per service).

In our study here, however, we are concerned with how far potential changes and innovations might reduce household demands on the environment, whilst retaining the natural diversity of household behaviours within each study. Reducing the emissions caused both directly and indirectly by households in our towns and cities is a significant international challenge. Reductions of $80 \%$ on 1990 levels by 2050 have been promised by the signatories of the Paris Agreement on Climate Change [15]. Clearly changes and innovations for households and the production systems that sustain them, will be key in achieving these changes.

Within households the different human needs that require answering have been divided into different Domains - namely, 'Living, Food, Mobility and Energy'. Clearly these domains interact as we try to keep warm, to cook our food, dispose of our household and food waste, travel to and from work and to the shops. But our current lifestyles are completely unsustainable as we emit far too much CO2 (and other Greenhouse gases) and use far too much energy and materials. For example, on average in the UK the material footprint is around $31,000 \mathrm{kgs}$ of 'inputs' per person per year - where the target level explored here is around 8000kgs [16] [17]. Several different approaches to the exploration of what might, should or could happen are possible. The model we develop here is neither simply about Forecasting nor Back-casting. It is an exploration of the possible reductions in the material footprints of households that different changes in households and improvements in infrastructure could produce. Our model takes into account the first and second order effects of an adopted innovation on the material footprint of the household concerned but is not as comprehensive or as difficult as building a full systems model that would link ecological, physical, economic, social and technological variables. It offers advice on the effectiveness of possible infrastructure changes and household innovations. 
In our approach here, instead of a case study, we adopt an ABM model approach and look at the impact of the separate adoption of various possible changes on the material footprint. This allows us to assess the relative impact of such changes for each region studied. We then use various approximations to estimate the combined impact of multiple different such modifications. In this way we avoid the difficulties of calculating the 'real' effects of households making all kinds of different decisions on which innovations to adopt and their overall effects on the whole system of connected interactions.

This approach allows us to calculate the overall material footprint of all the energy, materials, foods and wastes and to calculate how much it has been reduced. At present the countries that we have studied - UK, Germany, Spain and Finland have material footprints far greater than what might be 'sustainable'. Our aim is to study the effects of different innovations and changes that decrease this material footprint, and so move the system in question nearer to sustainability. We can then calculate approximately the additive effects of innovations made in the different household domains. Of course, this would not exclude the possibility that such factors as ecological and climate change for example, might occur for reasons on a larger scale than the region or country under study. In that case, the goals and reductions to be aimed for would need further revision and probably further interventions and changes.

Different kinds of changes can occur at different spatial scales. For example, the global scale for ecological and climatic changes, then the national or regional scale for infrastructural innovations, and finally the household level for very local technical and behavioural innovations. The model allows us to explore possible reductions in the material footprint as a result of particular innovations and calculate the reductions in $\mathrm{CO} 2$ emissions and compares them with those decided in international conventions such as the Kyoto Protocol and the Paris agreement [15].

The Agent Based Model used in this paper was developed previously [2]. It could explore the potential impact of household innovations and changes in reducing consumption and emissions and get closer to sustainability. However, in this paper we are concerned with the relative importance of different scale innovations: national or regional improvements of the 
infrastructure and household innovations. Clearly, changes that might be made to the material footprint of Grid electricity and the establishment of an adequate network of charging points for electric vehicles are innovations that cannot be made by individual households. They require national or regional decisions. Nevertheless, the ABM model that was developed can explore the relative impact of improvements made by households as well as those made to the 'system' within which they operate. For example, infrastructure innovations can affect the energy supply choices available and the practicality of switching to electric vehicles for mobility and transportation. The earlier work explored, within the current infrastructure, the impacts that household improvements could make in reducing their material footprint of inputs, emissions and waste production. And, the model shows us that although households can do much, their progress will be severely limited unless there are additional changes made to the underlying infrastructure by national and regional governments. The UK, Germany and Finland, even with the best household innovations still have material footprints well over twice the $8000 \mathrm{kgs} /$ person, seen by some as sustainable.

In this paper we want to show whether much cleaner grid electricity and its adoption for heating (the UK still has $80 \%$ gas heating), as well as the adoption of electric vehicles for transport, can get material footprints down to the greatly reduced level of $8000 \mathrm{~kg} /$ person. This can help to provide advice for policies and actions that will be required both at National/Regional and Household level and explore which policies and changes will be most important for the different countries studied.

First let us summarize the model and its results and show that a serious shift towards 'sustainability' will only occur if we not only allow Households to make innovations, but we also change the infrastructure available to them. Sustainability depends on changes being made at all the different levels in the system.

\section{The Agent Based Innovation and Change Model}

The model uses MATLAB software ("Matlab," 2016) and was developed initially to address the issue how close to 'sustainability' the diffusion of household innovations concerning material 
and energy reductions could make the region under study. How far might innovations and changes in lifestyles of a country or region reduce material footprints and emissions?

The UK, Germany, Spain and Finland were chosen as the candidates for these initial studies [2]. The outcome showed that all these countries did reduce their material footprints and emissions, but not by enough with only household innovations. Not enough to fulfil the requirements or the Paris agreement (15).

In this paper, we want to examine the additional effects of improving infrastructure as well as encouraging individual household innovations. The model addresses these questions by simulating artificial societies, with data selected from actual national statistics.

\subsection{Model design}

The model is 'agent-based' and corresponds to a population of households that stochastically adopt improvements and changes. Each agent corresponds to a household. The model is designed to explore the change in overall footprints and emissions of the system. It could show the kilograms of material consumption and the carbon emissions per individual. In other words, it calculates the changing load the households put on the environment, in terms of their reduced input footprints and reduced outputs of emissions and wastes.

Each household is viewed as having four different domains of activity:

1) Living - the size and occupancy of the house, the type of heating and water heating used.

2) Food - the source of food consumption, the method of cooking, the preparation involved and the waste.

3) Mobility - the travel of the house occupants, the number of cars possessed, the type of car or van (petrol, diesel or electric), the kms travelled. 
4) Energy - The energy supply and used by a household, the recharging of electric vehicles, and the presence or absence of Photo Voltaic energy or other energy generation.

These four household domains interact as a system, and together lead to the overall consumptions and emissions that are used to calculate the material footprint and emissions of households. The agent-based model uses actual national, annual data for the households and their four domains. This uses government statistical web-sites. This allows us to link the innovations and changes being studied with the decreases in emissions and material footprints.

A key element in the model design is the recognition of the integrated nature of households. The schematic in Figure 1 shows overlapping domains: green for food, red for energy, blue for living and yellow for mobility. Coloured lines show the relationships, for example, cooking food affects energy use, heating energy depends on house size, construction and occupancy, food waste is accumulated into household waste, as is waste from household occupancy. Household occupancy itself determines the food consumed and the energy used, and the energy used depends on the particular types of energy installed in particular households. Mobility emissions depend on fuel, choices of transport and miles travelled. Mobility fuel consumption resides in both energy and mobility domains, and so on.

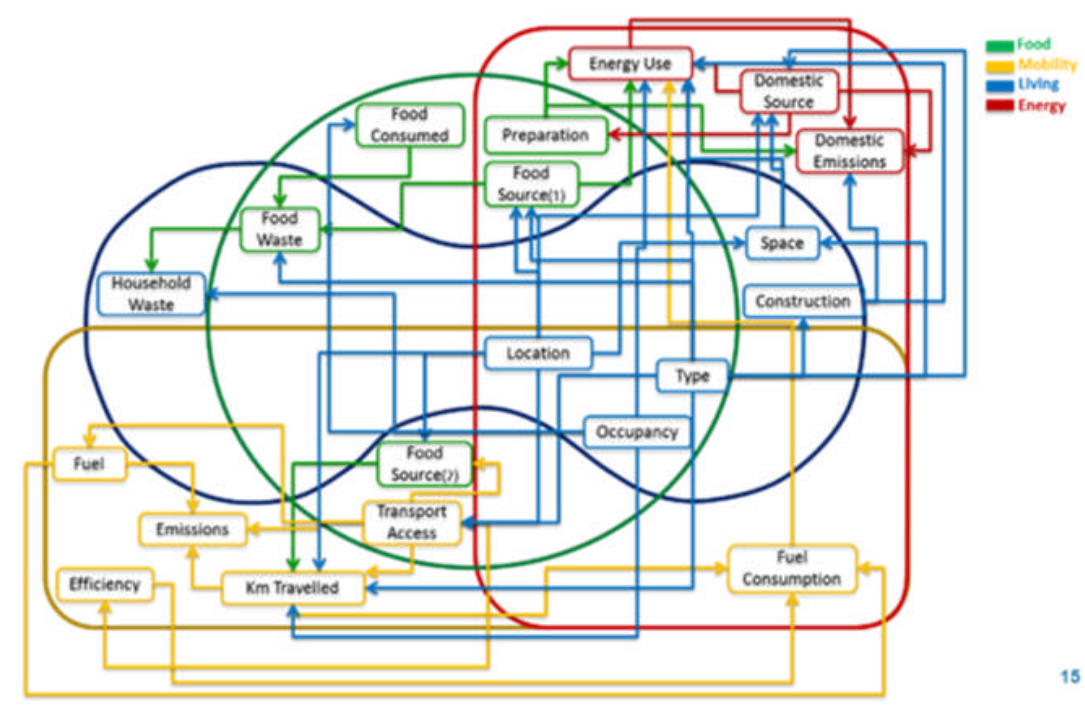

Figure 1: Integrated household domains: food, energy, living and mobility 
A detailed description of the model is given in [2]. Model initial conditions and the prevailing infrastructure are captured by the scenario data. For example, in the model used in the output shown below, we have picked 100,000 households from the millions available in the UK, Germany, Spain and Finland. The model can easily be set to take up to a million households - it just takes longer to run.

The household adoption of particular innovations or changes happens annually by choosing randomly among suitable, active agents (e.g. Agents without cars cannot get car efficiency allocations). Over time agents switch from inactive to active as concerns possible changes, and from active to adopters.

The model input requires three data sets in order to run: The Scenario/infrastructure, Innovation and Policy/Social adoption.

1. The Scenario/Infrastructure input data concerns the number of households and their different floor areas and occupancies. It also provides details of the number of cars per house, distances travelled, energy used, food and drinks consumed and the waste generated, etc. It describes the way that grid electricity is generated, and hence how 'clean' it is - that is the $\mathrm{CO} 2$ or Greenhouse gases associated with it. It also tells us the current choices of energy for households, for heating, hot water, cooking and running appliances. It also specifies the household occupancy, and car ownership.

This Scenario input file therefore specifies the material and energy 'footprint' of each household agent in the model run. The material and energy 'footprints' of households will reflect the quality of the collective infrastructure which is at a larger scale than individual households. This means that we can explore the impacts of cleaning up electricity production and moving from any coal/lignite, oil or gas to nuclear and renewables. In addition, we can make household heating less dependent on fuels other than electricity, and also move vehicles from being mainly 
petrol or diesel to being electric. With these assumptions, as in Figure 2, we can explore how much these 'collective' changes in infrastructure can reduce the material footprint and $\mathrm{CO} 2$ emissions per individual. This allows us to explore the relative importance of 'collective' innovations and those of individual households.

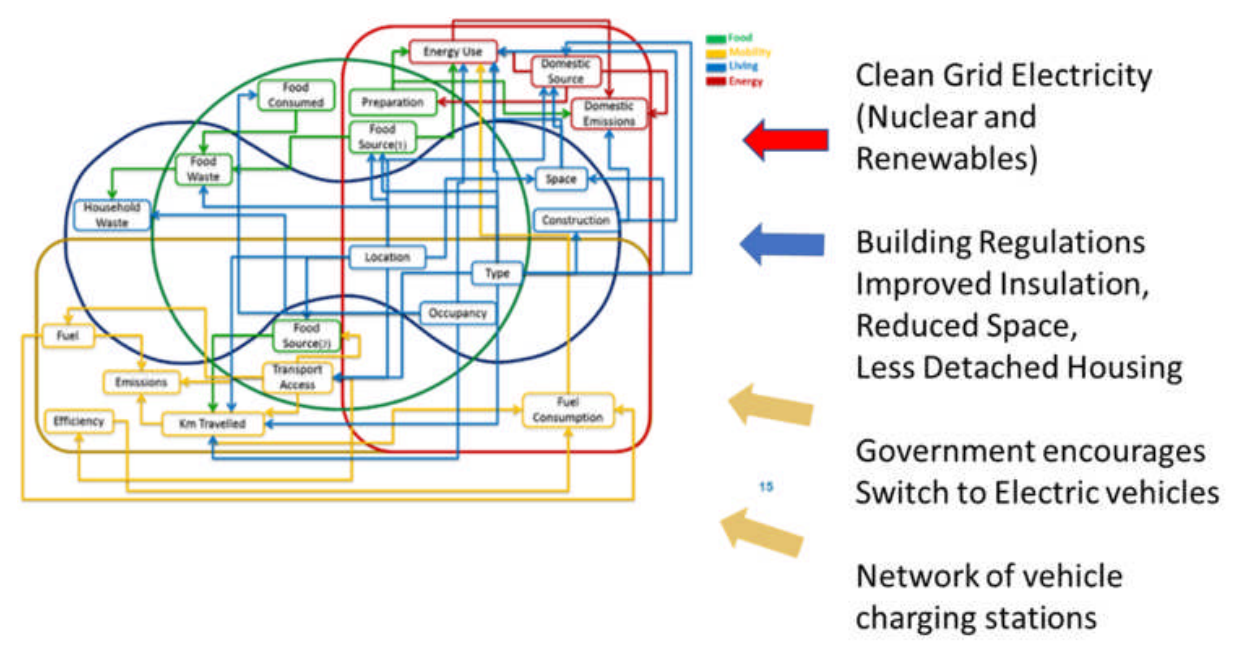

Figure 2. Each Household agent is situated with the infrastructural context of its location: clean electricity, an Electrical charging network, Building regulations etc.

2. The second input file required is the Innovation and Change Data. The changes are considered in all four domains of the Household. There are four improvements for the Living Domain, four for the Food, four for Mobility and two for the Energy Domain.

This gives us 14 types of change or innovations to explore and, in particular, to examine how much they may reduce emissions and material footprints. However, as we shall see it may well be the changes that are made to the 'infrastructure' of the system (input sheet 1 ) that are very important in attaining significant steps towards 'sustainability'.

3. The third input file required to run the model is that of Policy or societal change data. This can be used to explore the 'adoption process' and explore 'what ifs'. It can 
be used to examine the possible impacts of different policy options concerning the adoption of innovations. For example, there may be a known barrier to adoption of particular innovations, such as up-front capital requirements, or access to information. Or it might be clear that with improved trust or other societal change, that take-up could be improved, leading to more sustainable behaviour. The policy or social change data allows the user to provide an adoption rate related to the speed at which the adoption diffuses. The model assumes inertia in the system, and that there will also be some fraction of households who will not adopt innovations. Further, some households will not be eligible to take up an innovation, because they don't have the essential characteristics, for example, reducing the kilometres travelled by car is impossible for a household with no private vehicles. The adoption rate provided in the data results in a logistic (or sigmoidal) curve of adoption (based on feedback from active households), flattening out to reflect the maximum possible scale of adoption, provided a sufficiently high adoption rate is selected.

The model is described in detail in [2].

Households which do not possess a car are assumed to use bus and train in equal proportions. Travel as a passenger in a car is neglected, such that fuel consumption and $\mathrm{CO}_{2}$ emissions are attributed solely to household private vehicle schedule. Rural dwellers travel, on average, further than urban dwellers. It is assumed that rural dwellers travel 30-50\% (uniformly distributed) further than the average household, and urban dwellers travel 5-15\% less than the average household.

Consumption of energy, distance $(\mathrm{km})$ travelled, food consumed and wasted is based on household occupancy and is corrected for non-linearity and feedback effects (see the discussion below) for innovations that are adopted. The model assumes that $66 \%$ of the distance travelled by the hybrid is powered by the electric motor and the remainder uses the petrol engine. It is assumed that all buses and trains run on diesel; electric trains are neglected. 
ALL households are connected to the electricity grid. Gas use for cooking is assumed to be negligible as a large portion of household energy for cooking is provided by electricity (e.g. oven, microwave, toasters, grills).

The amount of energy generated by domestic PV systems depends on the amount of sunlight hitting the panel (varies with time of day, season and weather), the size of the panel, and the efficiency of the solar cells inside. An alternative local source for energy generation is an innovation that is accommodated by 'other local source' (e.g. heat pump); the purpose of the innovation might be for heating or other use, and it reduces energy demand appropriately and may contribute to emissions.

Heating is a function of dwelling size (i.e. space) and is not strongly dependent on occupancy. In contrast, the use of hot water and appliances is heavily influenced by occupancy. Households in the size range of $50-109 \mathrm{~m}^{2}$ are assumed to use the average household heating energy, as input by the scenario data. Households with a floor area less than $50 \mathrm{~m}^{2}$ are assumed to use half this energy for heating and houses with floor area above $110 \mathrm{~m}^{2}$ are assumed to use double the heating energy. Heating energy is multiplied by the household construction factor to account for dwelling energy efficiency. A grid reduction factor is present to account for a reduction in household emissions from using the electricity grid. Green energy contracts typically work by a "green" company pumping the equivalent amount of energy into the grid as is used by the contracted household. Therefore, while the impact on the grid overall is negligible, the individual household emissions essentially decrease.

Over time, households become active and decide to make the change, and the model shows the growing impact of 'adopters' on the improved and reduced demands for energy and materials made by the population. 
At each time step the model calculates first, how many households have changed from 'inactive' (not considering changes) to 'active' (potential adopters), and then how many of these 'actives' actually make the change in this time step. The model, which is about the diffusion of an innovation or of a change, calculates how many households in total have modified their material/energy footprint. It calculates for each timestep the resulting overall values of energy and material flows used by the region, as well as the $\mathrm{Co} 2$ emissions and the wastes generated. Over time the innovation spreads through the population, and the model can calculate the overall reductions in energy and materials used by the system, as well as the emissions and wastes generated.

The model sums the energy and material flows for the population under study, which consists of households that are not considering adopting an innovation, ones that are considering it, and households that have adopted the innovation. This allows the model to show the changing overall 'sustainability' of the population over time.

The model sums over the chosen subpopulation of household agents and calculates the changing levels of energy and material consumed as well as emissions and wastes generated.

\section{Infrastructural and Household Improvements}

The model allows us to see the relative importance of changes to national and regional infrastructures compared to that of household changes. Clearly, 'sustainability' depends on the adoption of improvements by households and infrastructures that reduce their material footprints and $\mathrm{CO} 2$ emissions. In this paper, we will examine the impact of changes in the national or regional infrastructure, such as the manner in which electricity is generated (how cleanly), how houses are heated, and how far the population of vehicles has adopted electrical power.

In the earlier paper [2], the adoption of Household Innovations was examined with today's infrastructure. It explored how far these might reduce material footprints and emissions in the 
UK, Germany, Spain and Finland. In this paper, however, we want to show how higher-level changes - improved infrastructure at a national or regional level - are in fact necessary in order to seriously reduce the UK, Germany, Spain and Finland material footprints and emissions. The model will show us how national and regional infrastructures affect material footprints per individual, and how, when household improvements are adopted as well, they reduce their material footprints and $\mathrm{CO} 2$ emissions very considerably.

The model essentially allows us to examine the impact of changes in the national or regional infrastructure such as the manner in which electricity is generated (how cleanly), how houses and heated, and how far the population of vehicles has adopted electrical power. However, it also can look at household initiatives, concerning the size and insulation of the houses, as well as various changes in distances travelled and vehicles acquired.

\subsection{The Changes in the Scenario/Infrastructure}

Let us explore the effects of assumptions concerning the 'scale' factors such as change to electric vehicles and the adoption of clean electricity on the energy and material consumptions and the $\mathrm{CO} 2$ emissions. For this we change the vehicle types from present proportions to possible future values with high electric vehicle ownership. In the table below we see that vehicles powered by Petrol: Diesel: Electric pass from the proportions $63 \%, 36 \%, 1 \%$ to $10 \%, 5 \%$ and $85 \%$. Similarly, we can shift home heating from (for the UK) from $80 \%$ gas to $80 \%$ electricity. We can also drastically clean up the electricity supply for example for the UK from being $.526 \mathrm{kgs} / \mathrm{kwh}(2015)$ to being $.103 \mathrm{kgs} / \mathrm{kwh}$. This is achieved by switching electricity production to fuel with little $\mathrm{CO} 2$ emissions. 


\begin{tabular}{|c|c|c|c|c|c|c|c|c|}
\hline \multirow{2}{*}{$\begin{array}{l}\text { Scenario } \\
\text { Mobility } \\
\end{array}$} & \multicolumn{2}{|l|}{ UK } & \multicolumn{2}{|l|}{$\mathrm{DE}$} & \multicolumn{2}{|l|}{ ES } & \multicolumn{2}{|l|}{$\mathrm{FI}$} \\
\hline & Current & Cleaner & Current & Cleaner & Current & Cleaner & Current & Cleaner \\
\hline \multirow{3}{*}{$\begin{array}{l}\text { Petrol Vehicles } \\
\text { Diesel Vehicles } \\
\text { Electric/Hybrid Vehicles }\end{array}$} & $63 \%$ & $10 \%$ & $66 \%$ & $10 \%$ & $66 \%$ & $10 \%$ & $74 \%$ & $10 \%$ \\
\hline & $36 \%$ & $5 \%$ & $32 \%$ & $5 \%$ & $32 \%$ & $5 \%$ & $26 \%$ & $5 \%$ \\
\hline & $1 \%$ & $85 \%$ & $2 \%$ & $85 \%$ & $2 \%$ & $85 \%$ & $0 \%$ & $85 \%$ \\
\hline House Heating & UK & & $\mathrm{DE}$ & & ES & & $\mathrm{FI}$ & \\
\hline \multirow{4}{*}{$\begin{array}{l}\text { Electric heating: } \\
\text { Gas heating: } \\
\text { Oil heating: } \\
\text { Solid fuel heating: }\end{array}$} & $10 \%$ & $80 \%$ & $20 \%$ & $80 \%$ & $27 \%$ & $80 \%$ & $47 \%$ & $80 \%$ \\
\hline & $80 \%$ & $10 \%$ & $37 \%$ & $10 \%$ & $47 \%$ & $10 \%$ & $0 \%$ & $10 \%$ \\
\hline & $3 \%$ & $3 \%$ & $26 \%$ & $3 \%$ & $17 \%$ & $3 \%$ & $12 \%$ & $3 \%$ \\
\hline & $7 \%$ & $7 \%$ & $17 \%$ & $7 \%$ & $10 \%$ & $7 \%$ & $41 \%$ & $7 \%$ \\
\hline Emissions & UK & & DE & & ES & & $\mathrm{FI}$ & \\
\hline Emissions $\mathrm{CO} 2 / \mathrm{kWh}$ electricity & 0.526 & 0.103 & 0.601 & 0.103 & 0.29 & 0.103 & 0.209 & 0.103 \\
\hline Sources & UK & \multicolumn{2}{|r|}{$\mathrm{DE}$} & \multicolumn{2}{|r|}{ ES } & \multicolumn{2}{|r|}{$\mathrm{FI}$} & \\
\hline Electricity from coal & $9 \%$ & $0 \%$ & $20 \%$ & $0 \%$ & $14 \%$ & $0 \%$ & $20 \%$ & $0 \%$ \\
\hline Electricity from lignite & $1 \%$ & $0 \%$ & $25 \%$ & $0 \%$ & $0 \%$ & $0 \%$ & $0 \%$ & $0 \%$ \\
\hline Electricity from gas & $42 \%$ & $20 \%$ & $13 \%$ & $20 \%$ & $21 \%$ & $20 \%$ & $10 \%$ & $20 \%$ \\
\hline Electricity from oil & $0 \%$ & $0 \%$ & $1 \%$ & $0 \%$ & $5 \%$ & $0 \%$ & $0 \%$ & $0 \%$ \\
\hline Electricity from nuclear & $23 \%$ & $20 \%$ & $15 \%$ & $20 \%$ & $20 \%$ & $20 \%$ & $33 \%$ & $20 \%$ \\
\hline \multirow[t]{7}{*}{ Electricity from renewables } & $24 \%$ & $60 \%$ & $26 \%$ & $60 \%$ & $40 \%$ & $60 \%$ & $36 \%$ & $60 \%$ \\
\hline & \multicolumn{4}{|c|}{ kgs per kWh electricity from coal } & 5 & & & \\
\hline & \multicolumn{4}{|c|}{ kgs per kWh electricity from lignite } & 10 & & & \\
\hline & \multicolumn{4}{|c|}{ kgs per kWh electricity from gas } & 1.2 & & & \\
\hline & \multicolumn{4}{|c|}{ kgs per kWh electricity from oil } & 1.3 & & & \\
\hline & \multicolumn{4}{|c|}{ kgs per kWh electricity from nuclear } & 0.1 & & & \\
\hline & \multicolumn{4}{|c|}{ kgs per kWh electricity from renewables } & 0.1 & & & \\
\hline
\end{tabular}

Table 1. The Changes in Scenario/Infrastructure (Current to Cleaner) from fossil fuel based inputs to cleaner, sustainable ones.

This allows us to study the impact on material/energy footprints and the emissions of the nations or regions studied. In this way we can provide evidence for the impacts of infrastructure development (clean electricity, car charging networks) and compare it to that of changes made by households. Clearly, the industries involved will also have to respond as well, providing far more wind turbines and solar panels, as well as electric vehicles and charging networks. But here we are mainly concerned with showing the actual impact possible by such large-scale changes, upon which we can add the effects of Household improvements. An important issue for us is the relative impacts of the infrastructural innovations compared with those resulting from the distributed effects of household improvements.

Our model should be able to indicate the relative importance of these two different scales of change and thereby show which particular investments or policies can have the most effect. The model reveals the uptake of each household improvement taken separately. However, we can estimate the additive effects of possible changes as well as the relative impacts of each 
improvement. This can also tell us which actions work best in the different nations and regions studied. This can therefore provide an excellent guide to policy and choices at present.

\subsection{Household Innovations}

The changes and innovations that are tested are from each household domain.

\section{Living Domain Changes and Innovations}

The changes and innovations made in the 'living' domain are:

1. Change type: The household changes from being independent to being part of a cooperative housing scheme. This reduces heat losses from each household and allows non-heat energy to be retained better, reducing heating energy required per person. The secondary impacts from this are reductions in heating, food waste, less space per person, less household waste, reduced cooking energy and the possibility of using local energy and food sources.

2. Improve construction: This improves the household energy efficiency. The improved insulation retains more of the non-heat energy of a household, reducing still further the amount of heat energy required. Secondary impacts are Reduced energy for heating and Reduced domestic emissions

3. Reduce space: The household reduces useable floor area, requiring less heating. Reduced house size also leads to greater heat retention from the non-heat energy used in the house and therefore to reduced energy for heating and reduced domestic emissions.

4. Reduce household waste: The household reduces recycled and/or non-recycled waste. 


\section{Food Domain Changes and Innovations}

Changes in the food domain are categorised by their primary impact on household food profiles as follows:

1. Reduce consumption: A household reduces the quantity of food consumed/purchased and gains the secondary effects of reduced food and household waste.

2. Change source: A household reduces distance travelled for food and/or waste generation from over-purchasing and/or packaging. The secondary effects are reduced $\mathrm{km}$ travelled, reduced fuel consumption and reduced emissions.

3. Preparation: A household reduces energy used for food preparation. The result is reduced energy for cooking, reduced total energy usage and reduced domestic emissions

4. Reduce waste: A household reduces avoidable food waste and also some household waste

\section{Mobility Domain Changes and Innovations}

Changes in the mobility domain are categorised by their primary impact on household mobility profiles as follows:

1. Reduce km travelled: The Household reduces the kilometres travelled by car, bus or train. This reduces fuel consumption, and mobility emissions, as well as domestic emissions for an electric car.

2. Change fuel: A household changes car fuel from petrol/diesel to electricity/hybrid. This will clearly reduce the consumption of petrol and diesel, and the generation of mobility emissions. However, it will increase the use of domestic energy and hence increase domestic emissions depending on how clean the electricity grid is. 
3. Change mode: A household changes the mode of travel (walking, cycling, car, bus, train). This will generally reduce mobility fuel use and emissions and make public transport more viable.

4. Increased Efficiency: By switching to highly efficient cars and trucks, as for example, hybrids with motors that stop when the vehicle is halted, and with braking energy recovery etc. we can diminish fuel consumption by $50 \%$.

\section{Energy Domain Changes and Innovations}

Improvements in the energy domain are categorised by their primary impact on household energy profiles as follows:

1. Reduce consumption: A household can reduce energy use in one (or several) of the five areas: heating, hot water, lights, appliances or cooking. This clearly reduces domestic emissions as well.

2. Change source: A household may install local energy sources (e.g. PV or other) or households may switch to a green energy supply. This will also reduce domestic energy consumption and emissions.

This shows us the list of possible household changes that will be tested. The important point in this work is that we can test them first with our current infrastructure (electricity production using largely fossil fuels, petrol/diesel transportation, house heating often using fossil fuels). Then we can test them improved infrastructure, cleaner electricity, more electric vehicles etc. This can allow us to show how limited are the reductions in material and energy footprints that can be achieved without these improvements in infrastructure.

\section{Model Output}

The 'infrastructure' sheet sets out the size and quality of the housing stock, the sources of energy and materials for living. It contains the data concerning the size and quality of insulation of housing, the occupancy, the means of heating and of producing hot water and cooking. It also provides data on the amounts of different electricity and gas used by houses, and their 
choices for heating, cooking, providing hot water and for running appliances of various kinds. The data includes the fuels used to make electricity, and the amount of nuclear and renewables, as well we the presence of absence of district heating. It also provides data concerning the sources and quantities of food and waste. This infrastructure input file also has the data concerning the travel that the population generates. It can be on foot, or bicycle but obviously, it is mostly about cars and public transport such as buses and trains. Cars are also split into diesel/petrol and electric/hybrids. By changing the data in the Infrastructure input sheet, we can examine its effect on the material footprint (kgs/person) and the emissions for the current situation and that of improved infrastructure - clean electricity, electric vehicles.

\begin{tabular}{|c|c|c|c|c|c|c|c|}
\hline & kgs/ind & Best & $\%$ Sust & $\mathrm{CO} 2$ & kgsCo2/yr & & $\%$ Red \\
\hline UK & 32523 & 19188 & $240 \%$ & UK & 3487 & 2127 & $39 \%$ \\
\hline DE & 53205 & 22878 & $286 \%$ & DE & 5646 & 2033 & $64 \%$ \\
\hline ES & 22362 & 10287 & $129 \%$ & ES & 3397 & 781 & $77 \%$ \\
\hline $\mathrm{FI}$ & 43777 & 18387 & $230 \%$ & $\mathrm{FI}$ & 5662 & 1982 & $65 \%$ \\
\hline
\end{tabular}

Table 2. The reduced material and emissions footprint with current infrastructure. In an earlier paper [2], Household improvements were applied to the current (2015) infrastructure. Only Spain got anywhere close to sustainability with their current infrastructure and with the best possible set of Household innovations (Table 2). This shows us that we shall not attain sustainability in the UK, Germany and Finland without doing more than simply adopting household innovations. 


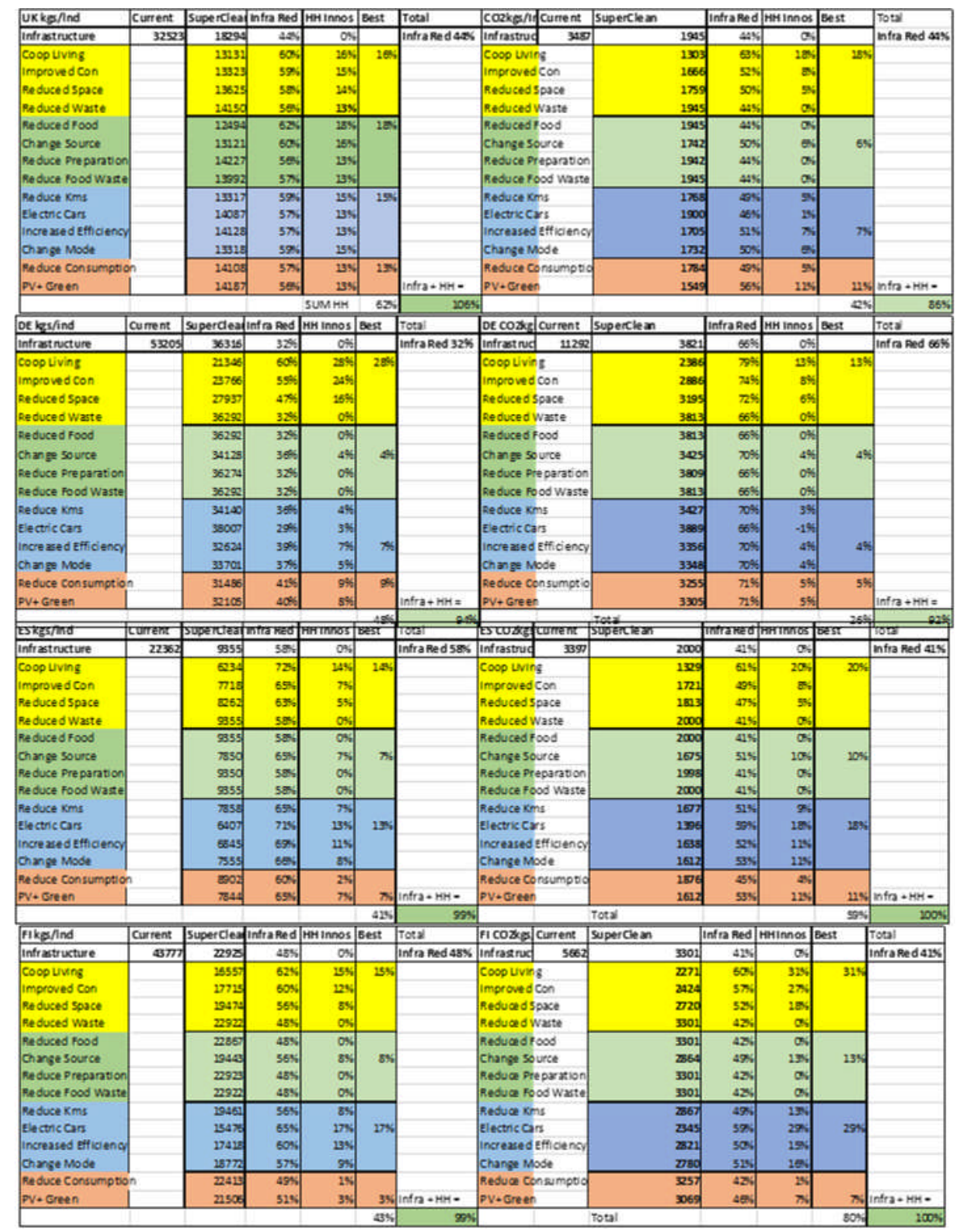

Table 3. The Reduction of Material footprint and emissions for UK, DE, ES and FI as the grid electricity is made largely fossil fuel free and transport moves to electric vehicles. Infra Red is the Reduction from Improved Infrastructure, Total is the Reduction from Infrastructure and Household Innovations.

The household change model runs for 35years from 2015 until 2050. It allows us to see how household decisions to make a particular change can improve the overall performance and sustainability of the region under study. The model demonstrates the reduction in material footprint and $\mathrm{CO} 2$ emissions per person in the UK, Germany, Spain and Finland as we run the 
model for all the different possible innovations of each domain. The comparison between the different countries reveals their different infrastructural 'starting situations', as well as how much the actual climate experienced by a region affects the difficulties that will be encountered to becoming 'sustainable'. For each of the countries we have the change in resource use and emissions resulting from the implementation of each innovation.

We next run the whole series of 2015-2050 again, Table 3, with cleaner electricity, $85 \%$ electric vehicles and $80 \%$ electric heating. We also indicate the result of adopting the 'best' innovation in each domain (Living, Food, Mobility and Energy) and estimate an approximate a 'total' effect by adding them. We can compare these new results with those without any improvements in infrastructure shown in Table 2. Instead, we now find the results shown in Table 4. In these results we see the impact of making the infrastructural changes in the second column of figures and then the impact of each household innovation separately. This enables us to see which changes had the most effect in each country, and thereby to give policy advice. We can then see how far the material footprint and $\mathrm{CO} 2$ emissions have been reduced. Even before we make any Household level improvements, the changed infrastructure makes an enormous difference in reducing the material and energy footprint.

\begin{tabular}{|c|c|c|c|c|c|c|c|c|c|}
\hline kgs/ind & \multicolumn{2}{|c|}{ Current S } & SC & & \multicolumn{2}{|c|}{ Infra Red } & \multicolumn{2}{|c|}{$\mathrm{HH}$ Innos } & Fin kgs/inc \\
\hline UK & \multicolumn{2}{|c|}{32523} & \multicolumn{2}{|c|}{18294} & & $44 \%$ & \multicolumn{2}{|c|}{$62 \%$} & 6952 \\
\hline DE & \multicolumn{2}{|c|}{53205} & \multicolumn{2}{|c|}{36316} & & $32 \%$ & \multicolumn{2}{|c|}{$48 \%$} & 18884 \\
\hline ES & \multicolumn{2}{|c|}{22362} & \multicolumn{2}{|r|}{9355} & & $58 \%$ & \multicolumn{2}{|c|}{$41 \%$} & 5519 \\
\hline $\mathrm{FI}$ & \multicolumn{2}{|c|}{43777} & \multicolumn{2}{|c|}{22925} & & $48 \%$ & \multicolumn{2}{|c|}{$43 \%$} & 13067 \\
\hline \multicolumn{2}{|c|}{ CO2kgs/In Current } & \multicolumn{2}{|c|}{ Cleaner } & \multicolumn{2}{|c|}{ Infra Red } & \multicolumn{2}{|c|}{ \& HH Innos } & Fin & al Emms \\
\hline UK & 3487 & & 1945 & & $44 \%$ & & $42 \%$ & & 1128 \\
\hline DE & 11292 & & 3821 & & $66 \%$ & & $26 \%$ & & 2828 \\
\hline ES & 3397 & & 2000 & & $41 \%$ & & $59 \%$ & & 820 \\
\hline $\mathrm{FI}$ & 5662 & & 3301 & & $41 \%$ & & $80 \%$ & & 660 \\
\hline
\end{tabular}

Table 4. The Reductions in material footprint and $\mathrm{CO} 2$ emissions from Infrastructural innovation and Household innovations. (Current $=$ Now, Cleaner, Infra Red $=$ reduction due to Infrastructure, \&HH Innos = added Household Innovations, Final = Total Reduction 


\begin{tabular}{|l|l|r|}
\hline & Clean E & kWh/ind \\
\hline UK & 372TWh & 5325 \\
DE & 806TWh & 12138 \\
ES & 162TWh & 3459 \\
FI & 45TWh & 8247 \\
\hline
\end{tabular}

Table 5. The approximate amount of 'clean energy' and 'clean energy/individual' required for the results above.

This tells us approximately how much the 'clean energy' supply has to increase is we are to attain the level of 'sustainability' indicated by the outcomes. This supply of clean energy will not only power the heating, hot water, cooking and appliances being used in households, but also the 'mobility' sector, which will have been transformed from being powered by $99 \%$ fossil fuels to $85 \%$ clean electricity. Clearly, this indicates that electricity will be doing much more than before, and the supply of renewable/nuclear electricity will need to be much greater than at present. This does tell us something of the scale of the problem, as it assumes that this much increased supply of clean electricity will be available and also that households will have adopted all the household innovations listed above and vehicles and charging stations will be ready. In fact, the amount of clean electricity generated in the four countries is already significant and Table 6 shows recent figures for clean electricity generation.

\begin{tabular}{|l|r|r|r|r|r|r|r|r|r|}
\hline Actual & Power Production 2018 & & & & & & \\
\hline TWh & Nuclear & Hydro & Solar & Wind & Bio & Total & Needed & Add? \\
\hline UK & 65 & 5 & 13 & 58 & 36 & 177 & 372 & 195 \\
DE & 76 & 17 & 46 & 112 & 52 & 303 & 806 & 503 \\
ES & 57 & 33 & 13 & 52 & 6 & 161 & 162 & 1 \\
FI & 23 & 14 & 0 & 6 & 10 & 53 & 45 & -8 \\
\hline
\end{tabular}

Table 6. The production (TWh) of clean energy in 2018 and the need for the future. [22] Increases over recent years have been very encouraging, but clearly, this initial growth has been based on the easier sources and locations. Presumably, doubling and trebling these figures may be increasingly difficult. But still we can see the scale of the problem that needs to be solved, and undoubtedly technology and innovations will occur to help us achieve the necessary increases. 
Clearly, compared to the limited reductions that were possible without the move to clean electricity, this shows us that reducing the material footprint and emissions sufficiently depends very much on improving infrastructure and also adding in the household improvements. However, we should note that these measures do not take Germany down to the often advocated $8000 \mathrm{kgs} /$ person. This means that it would require moving more completely to clean electricity, as our model runs assume that $20 \%$ of electricity is still generated from fossil fuels. For Germany this prevents it greatly reducing its material footprint and emissions. We have assumed the same 'clean' energy mix for Finland as for the others, but it is exceedingly unlikely that Finland would start to use gas, but would certainly increase its renewable generation. Another important factor is the difference in 'household occupancy' where the UK is 2.3, Germany is 2, Spain is 2.5 and Finland 2.1. This adds to the difficulty of reaching sustainable levels of consumption for Germany and Finland.

Governments also pledged to cut carbon emissions by 80\% of their size in 1990 by 2050 . Between 1990 and 2015 the UK had decreased Co2 emissions by 38\%. With the SC innovations the UK reduces it by a further $68 \%$, reducing them to $1128 \mathrm{kgs} /$ individual succeeding in its promises. Germany has reduced Co2 emissions by 30.8\% between 1990 and since 2015, with the innovations considered here we would have a reduction of $74 \%$ bringing the total reduction for Germany close to $90 \%$. Spain is different story, because from 1990 until 2009 they increased their Co2 emissions by a large increase (48\%) from 1990 until 2008, but since then it has dropped down considerably. With the aid of the improvements proposed here, Spain would experience a 76\% decrease in emissions/ind. Finland decreased it emissions by $26 \%$ from 1990 until 2015 . With the innovations proposed here it would reduce them by a further $88 \%$ bringing to within the desired value.

Another important message from this is that it tells us that unless governments make sure that their electrical generation is much 'cleaner' than at present, then plans to shift domestic and business consumption towards electricity would be mistaken. Any switch from gas domestic heating and hot water ( $80 \%$ of UK homes) to electricity, would lead to a significant increase in emissions, and quite contrary to the Green commitments that have been undertaken. Similarly, 
a switch from fossil fuelled cars, vans and trucks to electricity would have a favourable effect on $\mathrm{CO} 2$ emissions in Spain and Finland, but an unfavourable one in Germany. This shows us that changing over to clean electricity is a vital step towards a more 'sustainable' future. Another important point is that while electricity in produced from fossil fuels we must note that the process is only $45 \%$ efficient, so it takes more than twice as much fossil fuel energy to provide each kWh of electricity. Once electricity is produced by nuclear and renewables then we do not need twice the fuel and the emissions to generate it.

\section{Discussion}

This underlines the importance of a multi-level approach to reducing emissions and energy and material footprints. Climate change and sea-level rise require an international level of intervention and change. Attaining sustainability on the part of nations requires action at the national level for infrastructural changes such as

1) Electricity production to non-fossil fuels - Solar, Wind, Nuclear, tidal, waves, aerobic and anaerobic digestion etc.

2) Establishing and enabling a network of car/truck/bus charging facilities

But Households must also change and innovate as well

3) To make the switch to electric heating etc. and switch home heating away from fossil fuels such as gas, oil, coal.

4) A change to electric vehicles.

5) We also need to improve construction quality and insulation, more collective housing, reductions in vehicle travel, and PV adoption.

Reaching anywhere close to sustainability requires actions and change at the level of National and Regional systems, as well as for Households.

The diffusion of improvements within the Living, Mobility and Energy domains, are very important. As we see from our model output, a move towards more collective living - fewer detached houses - are the most effective innovation in all four countries. For the Food domain, 
the most effective change appears to be either reducing quantities or adopting closer, local sources.
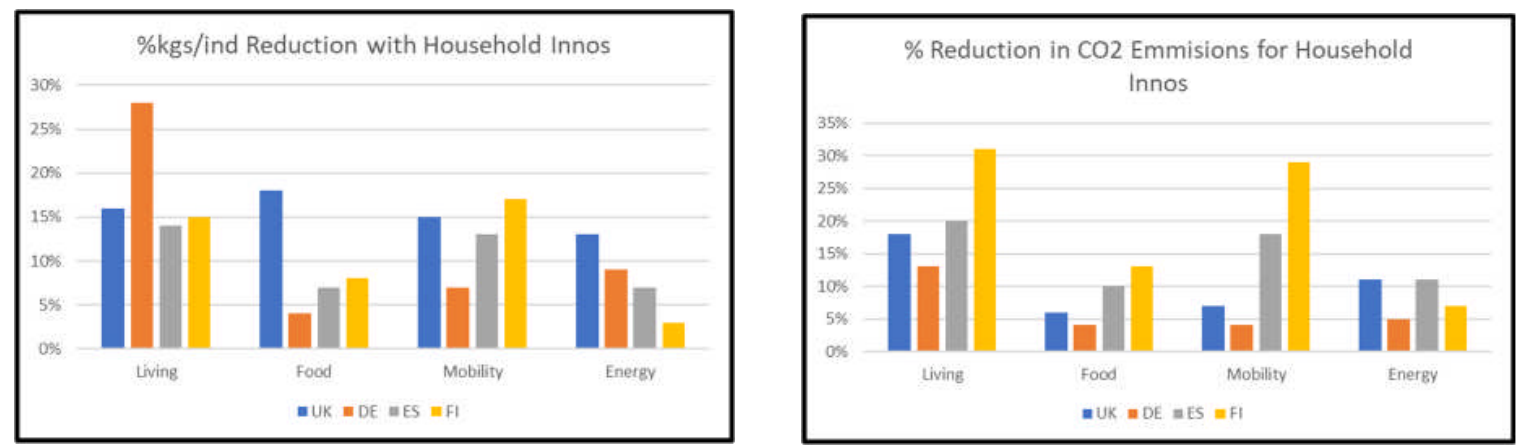

Figure 3. The best Household changes and innovations lead to different reductions in the material footprint and the emissions of the different countries.

The model shows some non-trivial differences in the effectiveness of improvements in the different household domains (Figure 3). For example, Germany seems to gain most from changes in the living sector, while the UK gets most from the Food sector. Germany seems to gain least from the food and the mobility changes, while the UK seems to gain most from the energy improvements. For emissions of $\mathrm{CO} 2$, Finland and Spain seem to gain most from the changes in living and mobility.

The model allows us to show the relative impact of national/regional infrastructural improvements compared to that from changes made by households. It also shows us how the 'improved sustainability' from the current situation reflects the fact that different countries are at different stages in making their systems more sustainable and that they face different challenges. For example, Germany has installed significant amounts of wind and solar energy, but also still burns lignite and certainly has a cold winter climate. In Finland, there is a very harsh winter climate, but houses are generally already well insulated and also benefit from a considerable amount of District Heating using excess heat from industry. The UK uses lots of gas for household heating, which is cleaner than coal but nevertheless is still a fossil fuel. The UK cannot reduce its material footprint below $8000 \mathrm{kgs} /$ person, without switching away from gas 
and adopting clean electricity. Spain benefits from climatic advantages compared to the other three countries and also has a higher occupancy per household than the others.

\section{Conclusions}

The Agent Based Model described in detail in a previous paper [2] was able to explore the role that households might play in reducing the material footprint and the emissions of the UK, DE, ES and FI. However, it showed that even with great efforts, only Spain came anywhere near a large enough reduction in material footprint and emissions. This paper therefore used the model to explore the impact of making important infrastructural changes to electricity production and to vehicles. That is, it moved to much cleaner electricity production and the development of an adequate network of charging places for vehicles. With these changes, and with the decision on the part of households to move towards electrical heating and to electric vehicles, the model was able to show that the UK and Spain successfully reduced their material footprint per person below $8000 \mathrm{kgs} /$ individual. However, Germany and Finland did not get to this level.

The infrastructural changes were clearly vital to the resulting decrease in energy and material consumptions, as well as carbon emissions, but it also required the household changes and innovations presented before. Both infrastructural and household changes were necessary in order to make large enough reductions. In other words, in addition to the household changes we have listed we shall only attain large the large reductions we need if we increase enormously the supply of clean electricity. We then also need to move home heating, hot water, cooking etc, and our travel and transport from fossil fuels to the clean electricity.

Here we have mentioned the suggested definition of sustainability put forward by the Wuppertal Institute which was a material footprint of $8000 \mathrm{kgs}$ per individual per year. This is a simple indicator that is easier to estimate than a complete study of the relevant physical, ecological and socio-political systems involved. It is clearly an initial indicator of the 'load' placed on the system per person. However, the idea that a static target such as this is what we 
should aim for is wrong. It may well be possible to move from purely 'exploitative' behaviours with regard to the ecosystem and physical surroundings, to a 'regenerative' behaviour that can eventually re-build our ecosystems $[7,8,9,10]$. Clearly, the IPCC report [1] that has come out recently tells us that we must take action rapidly if we are to avoid catastrophe, and that is the main focus here. What actions could reduce our material footprints and emissions to levels that may avoid catastrophe. The question therefore arises as to which actions and innovations are the most effective for any particular country or region. Our model provides a way of examining this, using real data with its actual diversity and variability, and looks at the impacts of the changes and innovations discussed, to see how far they can take a society towards a sustainable way of life.

As key innovations here, we have considered the impact of cleaner electricity production on the system, and we have supposed a remarkable switch to clean home heating with clean electricity and the use of electric vehicles. There are further areas of course that could affect the material footprint and carbon emissions of human settlements, such as, moving away from a meat-eating diet, which has enormous input requirements per $\mathrm{kg}$ and also very large Greenhouse Gas emissions. Also, there are the possibilities which we have not examined in detail, of the amount of food and waste recycling, as well as the question of changing spatial urban patterns of home, shopping and employment. There remain further avenues of potential reduction in energy and material consumption. However, we should not forget that in the period from now until 2050, we shall also experience more global warming, rising sea levels, and more violent weather patterns. Clearly, all these changes may make 'sustainability' all the more difficult and require even greater reductions in our material footprints. Nevertheless, the innovations and changes studied in this paper show us that we could make considerable progress towards sustainability by 2050 .

\section{Acknowledgements}

This research is part the large-scale project 'Sustainable Lifestyles 2.0: End User Integration, Innovation and Entrepreneurship (EU-InnovatE)'. The project was coordinated by the Technical University of Munich, Coordinator: Prof. Dr. Frank-Martin Belz, TUM School of Management, 
Alte Akademie 14, 85354, Freising, Germany, Phone: +49 816171 3279. E-Mail:

frank.belz@tum.de.The project has received funding from the European Union's Seventh Framework Programme for research, technological development and demonstration under grant agreement no. 613194. We would like to thank Julia Binder at the TUM, Angelina Korsunova for Finnish data, and Spanish data from Xavier Fernandez i Marın and also J.M. Gonzalez de Durana. We would also like to thank a reviewer for most insightful comments.

\section{References}

1. IPCC report, 2018, Global Warming of 1.5C. Summary for Policy Makers

2. Allen P, Robinson M, Butans E and Varga L, Innovations for Sustainable Lifestyles - An Agent Based Model Approach, Sustainability Science, July, 2018

3. Allen P.M., 1982, "Evolution, Modelling, and Design in a Complex World", Env\&PI B, March, https://doi.org/10.1068/b090095

4. Allen P M, 1990, "Why the Future is not what it was", Futures, Volume 22, Issue 6, JulyAugust 1990, Pages 555-570

5. Boulton J, Allen P.M., Bowman C, 2015, “Embracing Complexity: Strategic Perspectives for an age of turbulence", Oxford University Press, Oxford.

6. Allen P M , 2017, "Complex Evolving Social Systems: Unending Imperfect Learning", Chapter 2 in Handbook on Research In Complexity, Eds Mitleton-Kelly, Paraskevas and Day, Edward Elgar, 2018

7. Mang P \& Reed B, 2012; "Designing from place: a regenerative framework and methodology", Building Research \& Information, 2012 - Taylor \& Francis

8. du Plessis, C. (2012). Towards a regenerative paradigm for the built environment. Building Research \& Information, 40(1), 7-22.

9. Wahl Daniel Christian, "Designing Regenerative Cultures", Triarchy Press, Bridport, United Kingdom

10. Lorena F. Axinte, Abid Mehmood, Terry Marsden \& Dirk Roep (2019), Regenerative cityregions: a new conceptual framework, Regional Studies, Regional Science, 6:1, 10, pp117- 
129, DOI: $10.1080 / 21681376.2019 .1584542$

11. Jason Palmer, lan Cooper, United Kingdom housing energy fact file, DECC 2012

12. David Dodman, "Blaming cities for climate change? An analysis of urban greenhouse gas emissions inventories", Environment and Urbanization 2009; Vol 21(1): 185-201

13. Ivanova D., Stadler K., Steen-Olsen K., Wood R., Vita G, Tukker A, and Hertwich E.G., 2016, Environmental Impact Assessment of Household Consumption. Volume 20, Number 3. Journal of Industrial Ecology

14. Bruno S. Silvestre, Diana Mihaela Jîrcă, Innovations for sustainable development: Moving toward a sustainable future, Journal of Cleaner Production, Volume 208, 20 January 2019, Pages 325-332

15. Paris agreement on Climate Change, November 2016. European Agreement on $80 \%$ reduction in CO2 1990 emission by 2050. In the UK, Alex Bowen and James Rydge,2011, "Climate change policy in the United Kingdom", Policy paper by Centre for Climate Change Economics and Policy and the Grantham Research Institute on Climate Change and the Environment, LSE.

16. Lettenmeier, M, Liedtke, C, Rohn, H. (2014). “Eight Tons of Material FootprintSuggestion for a Resource Cap for Household Consumption in Finland", Resources, 3, 488515; doi:10.3390/resources3030488, ISSN 2079-9276, www.mdpi.com/journal/resources

17. Rijnhout L. and Lorek S., 2012, with inputs from the project consortium, project advisors and the European Social Platform on Sustainable Lifestyles EU Sustainable Lifestyles, Roadmap and Action Plan 2050, "Pathways for enabling social innovation and behaviour change"

18. Modelling sustainable energy futures for the UK, Peter Allen and Liz Varga, Futures 57 (2014) 28-40

19. Robinson $M$, Varga L, Allen $P$, An agent-based model for energy service companies, Energy Conversion and Management 94 (2015) 233-244

20. Ritthoff, M.; Rohn, H.; Liedtke, C. Calculating MIPS-Resource Productivity of Products and Services, 1st ed.; Wuppertal Spezial 27e, Wuppertal Institute for Climate, Environment and Energy: Wuppertal, Germany, 2002 
21. Lettenmeier, M., Rohn, H., Liedtke, C., Schmidt-Bleek, F. Resource Productivity in 7 Steps. How to Develop Eco-innovative Products and Services and Improve Their Material Footprint; Wuppertal Spezial 41, Wuppertal Institute for Climate, Environment and Energy: Wuppertal, Germany, 2009.

22. Sandbag:The European Power Sector in 2018, Up-to-date analysis on the electricity transition. AN ANALYSIS BY Sandbag, 40 Bermondsey Street | London, SE1 3UD | UK and Agora Energiewende, Anna-Louisa-Karsch-Straße 2 | 10178 Berlin | DE 